\title{
Prime Time: The First 6 Weeks Adjusting, Belonging, and Thriving in College
}

\author{
Karina Beras
}

\section{Program Introduction}

Entering college as a first-year student or going back to a college campus as a returner or transfer student can prove to be an exciting yet difficult time for a myriad of reasons. The transition and adjustment to college, or a new academic year, looks different for all students and can create much anxiety as they negotiate commitments and expectations. The first six weeks of the academic year prove to be a critical time in determining student success. Social and academic adjustments in the first few weeks are indicative of student persistence (Woosley, 2003). However, the importance of the first weeks is not always evident to students, and many end up having an imbalanced approach to the new academic and social lifestyle. For first-year students, the start of college brings about a new sense of freedom but also a change in family and friendship dynamics, particularly if they have chosen to move away from home. For returning students, the range of emotions can vary greatly depending on factors like their academic standing, living arrangements, unresolved friend-group conflict, and more.

The college experience is full of transitions that students are not always prepared to navigate. In my capacity as Program Coordinator, with responsibilities over new student orientation at Barnard College, I recognized that students operate on information overload during orientation, which they are not always able to retain or contextualize. Based on observations, informal conversations, and assessment feedback, we learned that many first-year students were feeling unsteady and felt ill-prepared to start classes. As an institution, we had an area for growth and a responsibility to better support our students' integration into the college and the first semester post-orientation. As such, I developed a first-year experience programming series to help acclimate and support first-year students in the changeover period from high school, to orientation, to college living. There are two main reasons why I introduced this initiative: 1) we needed a program to help first-year students transition into the collegiate environment more seamlessly, and 2) many of our students still struggled with making connections, lacked awareness of campus resources, and shared feelings of insecurity about life beyond college. The series, titled Barnard Bearings, focuses on providing students with practical skills to help them succeed not only as students but also as young, quasi-independent adults.

Barnard Bearings, an alliterative ode to our campus mascot, was implemented 
in Fall 2017 after noticing a disconnect that occurred for students after they completed our weeklong orientation program followed by our welcome week. The disconnect emerged for first-years, transfers, and returning students alike, many noting that academic pressures, off-campus internships, and campus involvement often left them missing out on key aspects of the college experience. Students mentioned wanting to meet more people, which proved to be especially difficult between students of different class years, given our dispersed residential buildings. They also wanted to learn hard skills like money management and self-care practices necessary for their survival not only as college students but also as newly minted, even if temporarily so, New York City residents. To further expose our students to on- and off-campus resources, we coordinated all our workshops and sessions in collaboration with campus and community partners. Our promotion included giveaways to incentivize student attendance, since the programs and workshops were voluntary. Additionally, the giveaways correlated with the topic we discussed each week and helped in office branding.

\section{Program Description}

Relationships are formed on a daily basis across college campuses. However, these relationships are sometimes unhealthy, non-consensual, and uncomfortable to navigate. With that in mind, our first program was in collaboration with our Program Coordinator for Prevention Education and consisted of a speed friending activity. The session focused on how to form healthy relationships via a series of questions, scenarios, and reflections. The small chatter, movement around the room, and self-reflective questions allowed students an opportunity to meaningfully engage while learning to do so using agreed-upon forms of engagement and in a setting with unaltered attendance. We welcomed students to attend the event regardless of identity, academic/extracurricular interests, or class year, all of which often pre-determine social settings on college campuses.

Forming and maintaining relationships requires balanced and intentional time management. Our second session focused on time management and organization, since failing to grab a hold of these early in the semester can leave many students in a downward spiral toward midterm season. In partnership with the Senior Associate Director of Academic Success and Opportunity Programs, this session required students to complete weekly schedules that included class schedules, reading/writing time, meal times, extracurriculars, sleep, self-care practices, and time spent with family and friends be it physically or virtually. The idea of including all plans other than academics, extracurriculars, and campus jobs on the calendar seemed like a novel idea to students. It highlighted that they took a disparate approach to time management and lacked a comprehensive view of their multiple identities and needs beyond being students.

Students' approach to completing course assignments is indicative of time management skills. College study habits, writing styles, and reading loads are different from those of grade school; however, the realization of this shift in practice and expectations is not always common knowledge for students. Mentor- 
ship programs and peer-to-peer tutoring are tremendous resources for students to learn more about the different academic landscape in college. One of our sessions focused on writing in college and was led by student writing fellows. The session garnered the attention of many international first-year students and transfer students who shared feelings of concern about academics in a new country or in a new school. The peer-facilitated session created a more balanced dynamic and an exchange of first-hand anecdotes between students on feelings of imposter syndrome, insufficient understanding of course expectations, and more.

Imposter syndrome affects college students in a variety of ways, be it from insecurities around academic ability to believing that they do not fit in due to a lower socioeconomic status. Students at Barnard often voice concerns about their inability to fully enjoy New York City given the high cost of living. Though the institution offers opportunities for students to participate in off-campus events that expose them to New York City, these are not guaranteed and still leave low-income students feeling disenfranchised and further marginalized when they cannot afford other options. But despite socioeconomic status, students shared interest in learning how to live on a college budget and how to manage the income available to them. In response to this request, we invited the local credit union to host a workshop on credit and budget management. Students were presented with ways in which they could begin to build credit, balance budgets, and maximize financial resources. At the same time, credit union representatives gave students the opportunity to ask questions about planning for loan repayment post-graduation, making financial decisions that best aligned with their income, and knowing which credit cards to sign up for and how and when to use them. Students walked away with practical skills to excel in financial matters and with individualized budget sheets.

Academic acclimation, financial fluency, and social stability are all part of student well-being. However, students must also learn how to practice self-care for physical and mental health. I decided to focus on self-care towards the end of the programming series, at a time when students may begin to feel the effects of a heavy coursework, daylight savings time changes, and Fall break not coming fast enough. In partnership with our Health Promotion Program, we created a space for students to explore definitions of self-care, learn about free or inexpensive ways to practice self-care, and plan out times when they would practice self-care and selflove that was not in response to crisis. Additionally, the session served to promote the non-medical services that our college provides to support students in finding a balanced approach and learning to live well.

Reflection is an important part of student learning. Our final session culminated with a recap of previous sessions and centered on actionable goals to ensure a successful academic year. Students referred to information they wished they had known prior to orientation, reflected on lessons learned throughout the first six weeks, and relayed their goals for the semester. The reflective nature of this session allowed students the opportunity to see how far they progressed, to pay it forward to younger and/or incoming students, and to hold themselves accountable to the goals they wish to achieve in this academic year. The recommendations and reflections have inspired the creation of a guide for incoming students but have 
also pushed us to think about transitions beyond the first year. While this program was intended for first-year students, the demographic of students who attended the workshops surprised staff as an unanticipated outcome. Upper class students participated in all of the workshops, which aided in community building between class years and in peer-to-peer teaching and learning. Moreover, it confirmed that student transitions happen throughout all stages of their undergraduate career and are not isolated to the initial start of the college experience. The convergence of academic and social support workshops, peer relationship development across class years, and concerted efforts across offices and departments to follow a similar theme in transition- and persistence-related programs could bring about radical change in how students experience and describe the start of the academic year.

Transitioning to college brings with it with much excitement for change and new experiences. It also ushers in unknowns and at times apprehension. Barnard Bearings, a new initiative with a strong focus on cross-campus collaborations and engaging new incoming students, highlighted that the first six weeks can be a danger or an engagement zone for students across the board regardless of class year standing. The program has created avenues for increased collaboration among campus partners and a newly formed First-Year Experience Working Group for coordinated efforts. The proper integration and transition into the academic year is important for student success and retention regardless of class standing. If we want to have a stronger sense of community and improved mental health amongst our students, then we should actively ensure that students start the academic year not with self-doubt but with self-assurance.

\section{References}

Woosley, S. A. (2003). How important are the first few weeks of college? The long term effects of initial college experiences. College Student Journal, 37 (2), 201207. 